\title{
The Relationship between Learning Styles and Students' Identity Styles
}

\author{
Sara Alavi*, Hassan Toozandehjani* \\ Department of Psychological Sciences, Faculty of Humanities, Neyshabur Branch, Islamic Azad University, Neishabur, Iran \\ Email: h.toozandehjani@ymail.com
}

How to cite this paper: Alavi, S. and Toozandehjani, H. (2017) The Relationship between Learning Styles and Students' Identity Styles. Open Journal of Psychiatry, 7, 90-102.

https://doi.org/10.4236/ojpsych.2017.72009

Received: November 25, 2016

Accepted: April 27, 2017

Published: April 30, 2017

Copyright $\odot 2017$ by authors and Scientific Research Publishing Inc. This work is licensed under the Creative Commons Attribution International License (CC BY 4.0).

http://creativecommons.org/licenses/by/4.0/

c) (i) Open Access

\begin{abstract}
The aim of this study was to investigate the relationship between learning styles and identity styles Students. The study consisted of all high school students and community solidarity (second period) in the 2014-2015 school year resident of the city of Sabzevar that 100 people were selected by multistage random cluster sampling. Kolb's Learning Styles Inventory Tool questionnaire identity styles Bennion-Adams used the results showed that successful identity styles between style concrete experience, reflective observation, abstract conceptualization and active experimentation students have a significant relationship. Among the components of a successful style only concrete experience, reflective observation and active experimentation to predict and successful identity and disoriented style of abstract conceptualization learning style to predict. Also a significant relationship between the identities of the student field does not exist. Among the students, there is significant gender identity style making.
\end{abstract}

\section{Keywords}

Concrete Experience, Reflective Observation, Abstract Conceptualization, Successful Identity, Confusion, Active Experimentation, Learning Style, Identity Style

\section{Introduction}

One of the things that the seventh decade of the twentieth century has been considered in educational research on learning styles of students contents. Other activities, such as learning are work and work is very difficult in some cases. The role of learning in all the scenes showing life as it is closely related to the behavior and actions of man. Learning can be defined in various ways. The best definition ever offered to learn the definition of [1], the learning process is learning *Sara Alavi: B.A. in General Psychology; Hassan Toozandehjani: Assistant Professor of Psychology. 
to create relatively permanent changes in behavior or behavior that arises from experience and it cannot be temporary state body like illness, fatigue or drugs caused attributed. Thing to notice here is that, unlike talent is the ability, not the ability of learning styles. Hence, learning style does not refer to the learner learns how to get to how well the learning comes from, so people according to their individual differences in learning styles of different uses would be light as a way of learning to the learner in their learning it prefers to be defined in other ways. That's why some educational psychologists, including [2] term preferred learning styles learn to better understood and define the following offers:

The friendly person to study and learn, such as the use of images instead of books, working with others rather than just working out, structured learning situations versus non-structured situations and so on.

This study is a new study in this field especially in Iran; which was the main reason to carry out this study.

\section{Literature Review on Learning Style and Identity}

Learning style or preferences of the different individuals, however, they can be divided into three groups: cognitive, emotional and physiological divided [3]. A concept that is used to supplement the input behavior and the factors influencing learning is supposed to be learning styles [4]. Since students have different learning styles and the different learning styles affect learning and academic achievement, teachers are aware of how and a variety of students in the use of different learning styles.

Teacher dealing with different learners must accept that each of them may be in a specific style of learning to do homework and learn the latest of its regular; so we must be prepared to handle any of your students have learning style.

It is not possible to say that a learning style is better or worse than other styles. Expression is more correct to say that, depending on the circumstances and issues may be good or may not learn any style. However, teachers should not lose sight of individual differences love, but always have opportunities to learners and allow to different situations and on different assignments proper styles to apply and get advantage [5].

Learning is a process of adaptation and compromise important and no doubt all the amazing progress today is born of human learning [6]. Learning is the process of acceptance and processing of information that takes place in different individuals alike. In fact, the speed of learning and learners' academic progress is not always the same [7]. Several factors affect academic achievement following day. One of these factors is learning style can affect the learning process. By definition, a behavioral habit and distinctive style learning for knowledge, skills or open conflicts through study or experience or manner that is sweeping the Learning to prefer other means [8].

According to experts or cognitive learning style preferences of people to obtain, maintain and modify information makes it clear that the adoption takes place according to their IQ [9]. 
Studies have shown the efficiency of learning through teaching methods, learning styles or a combination of these two factors is formed. The method of training alone or with the help of learning styles in some cases, significant differences are created, but not all aspects of satisfaction, achievement and performance measures [10].

[11] emphasizes that understanding learning styles for learners and educators is essential. In fact, there is a valid tool for learning style learning style can lead to a more accurate understanding and based on that knowledge to learners to enhance the learning and help them strengthen self-actualization.

In terms of learning styles defined beliefs, preferences and behaviors that people have used to learn in a given situation. These styles of hand on the basis of individual differences and on the other hand are formed under the influence of the environment [12].

Individual learning styles are a direct reflection of the psychological and cognitive factors and also on the individual styles of learning to respond to specific stimuli [13]. Categories kind of learning styles, Kolb's learning style. Kolb in 1984, the most useful model inspired by the works of Kurt Lewin describes the process of adult learning as experiential learning styles presented. The styles correspond with a model of the learning process [14].

Converging of learning style by combining two or two-step methods of abstract conceptualization learning, abstract thinking and active experimentation is obtained. This style is most capable of employing qualified individuals learn practical ideas and theories and for issues and make decisions based on solutions that they find.

For their technical assignments on social issues and the individual is preferred. The people in formal learning situations, experience new ideas, simulations, laboratory activities and prefer practical work, individuals with this style of learning, the more technical work, engineering, medicine and law tends [15].

Divergent learning style: This style of learning, learning styles experiences in combines objective and thoughtful observation. People with this learning style, they see concrete situations from different angles. Their approach to the situation is seen to act [16] [17].

Assimilate learning style comes from the combination of abstract thinking and reflective observation. The participants learn and understand the learning style in extensive information and turn it into short, precise and logical are capable. Their ability to learn, think and look up. From the perspective of the theory that logically correct on theories that have practical applicability, are preferred. These people are more interested in abstract concepts to people and to the interest of systematic planning often work in the Research and Planning. People with this style more attracted to science, mathematics, chemistry, economics and social sciences are [18].

Adaptive learning style is a combination of two ways of gaining concrete experience and active experimentation. The participants learn this style of marketing and sales jobs are more successful than others prefer to work with people 
who give them what their goal is to identify and work environments [19].

Research literature indicates that learning about different learning methods with sex, level of education and their academic field. More men tend to experience objectively, while women usually are more reflective [20]. [21] have expressed divergent ways students learn humanities and social sciences, physical sciences students and students absorbing Engineering - Engineering is convergent [22].

Adolescence is a period of transition from childhood to adulthood. In the course of a person, a child familiar space left inside the new stage. The transition from stage to stage is associated with several issues that one must with the changing biological, cognitive and physical, with expectations of parents, peers and school with a better fit to adapt to changes. Entry to the course, internally with the formation of abstract thinking, memory and emotional maturity begins a new chapter in the lives of adolescents' identification marks that it is in the center.

Ericsson was the first theorist of psychoanalysis that the importance of the formation and preservation of the identity of the stages of life including teenagers stressed [23].

Marcia (1966) to operationalize the concept of identity, fundamental both in theory are explained Ericsson that presence or absence of period of crisis as well as presence or absence of a clear and firm commitment with a sense of it.

During the crisis period when the teenager is expected to explore rather than seek to acquire earned a strong commitment to the values and beliefs [24]. The main task of identity formation begins in high school and continued through college-age seriously.

Unlike the clutter structure (deconstruction) that people experience in their early teens, high school students are more likely to forgive or restructure their identity restructuring [25]. While people in their early teens from Children concepts in the break, adolescents in high school are often physically cohesion or reorganize their emotional, sexual feelings, evaluation of current capabilities and roles or their expectations are trying. Adolescents in high school are often physically cohesion or reorganize their emotional, sexual feelings, evaluation of current capabilities and roles or their expectations are trying.

Marcia most complete picture of the regular process of growth during the formation of identity is provided. Access to its internal organization, including its construction of a system of beliefs, desires, ideas, skills and knows the history of separation. His true identity formation in adolescence Ericsson in detail and explained more carefully and delicately, Ericsson created a model of the theory, but instead often used the word crisis of exploration. Marcia basic variables theory has been studied in two dimensions is conceptual exploration and commitment. He chose these two criteria to individuals based on identity puts them in one of four modes. Refers to the questioning of juvenile actively explore and value the different cases of identity. Commitment refers to the situation where the teenager had achieved strong belief [26].

Based on these two criteria: 
Identity of foreclosure: the case of the identity of the young person without being told that the crisis is related to the age and experience, his commitment is formed. Identity of moratorium: the sense of identity in the young is said to have experienced a crisis of this age, is actively looking for commitment, but commitment is not based on person. Identity of diffusion: the young state of identity crisis, according to a person not related to the age, experience and commitment is not an attempt to shape.

Identity of achievement: the sense of identity in the young is said to have experienced a crisis of this age and then he made a commitment to actively pursuing a strong sense of identity has been lost [27]. In the latest research on various modes of identity, researchers have also considered a fifth shape.

[28] in study, group of young teenagers and those in late adolescence were tested. They reported five cases of identity that include: 1 . The successful identity, 2. Early identity, 3. Postponed Identity, 4. Searching moratorium, 5. Confused and wandering identity.

The five groups are significantly in variables such as personal characteristics, psychological problems and family relationships to be clean. [20], before their fifth mode called identity was shaped half. Research shows the evolution of identity development in adolescence with their development levels of abstract thinking, judgment and moral transformation evolved levels of internal locus of control has positive correlation and difference between identity statuses of mental health is significant [12] [13] [14] [15]. About sex and identity acquisition bases, numerous studies have been done on some of them referred to the effect of gender on identity authentication [8] and in others the relationship between the two has been reported [15] [16] [18].

[3], we review the results of research that has been done during 30 years from 1966 to 1955; suggest that identity transformation process is the same in both sexes. [6] on this issue that differences in learning styles may compliance and consistency in how effectively students with an academic environment.

In addition [5] in their study concluded that some teenagers and adults can all day but all the styles, identity styles of no prominence at a time and in any position, depending on the circumstances, one of the leading styles. According to what was said the study is whether a significant relationship between learning styles and identity styles among students?

\section{Method}

The present study is correlational.

\section{The Static Population, Sample Size, Sampling Methods}

All students in the high school girls and boys (second period) in 2014-2015 academic years are enrolled in schools in Sabzevar city. 100 people were selected by multistage random cluster sampling. This means that the second round of high schools provide a list of all schools that among them randomly select two schools for girls and two boys schools and then re-randomized samples from the girls and boys in first and third grade. 


\section{Tools}

Kolb's Learning Styles Questionnaire: Kolb Learning Style Inventory includes 12 such that for each of four options suggested. Each option represents one of the four methods of learning by concrete experience, reflective observation, abstract conceptualization and active experimentation. Of the subjects, their proposed options to suit their preferred learning style of their ranking score of 4 to 1. [5] [6] [7] [8] [9] through the analysis of data have confirmed the validity of the test and Kolb (1985) using Cronbach's alpha reliability coefficient reported is as follows: Active experimentation 0.78, Abstract conceptualization 0.83 , interactive view 0.73 and objective experience 0.83 .

Identity Style Inventory Bennion-Adams: Based on the theory of Ericsson and Marcia about identity has been developed. The questionnaire consists of 64 items and includes four subscales are. Subscales of this questionnaire are: 1. subscales identity confusion; 2. subscales identity is formed early; 3 . subscales identity postponed; 4 . subscales identity of progress.

Each subscale consists of 16 items. The subscales state of confused identity, identity is formed soon; they determined the identity postponed and identity development. Items on each subscale in the two areas of general ideological issues (jobs, religion, politics, philosophy of life) and interpersonal (friendship, dating, entertainment, sexual role) is. In fact, it can be said that each subscale, self-contained within is also ideological and interpersonal subscales.

The validity of is calculated using internal consistency and test results have been satisfactory. The validity of test scales between $40 \%$ to $73 \%$ and reliability of the test was $78 \%$.

Convergent validity of the test were examined by divergent /concurrent methods and validity and the results obtained under the convergence and divergence between the subscales scale up to $93 \%$ and $76 \%$, respectively [7]. The reliability and validity of the questionnaire by Rahim Nezhad (2000) 0.59 to 0.81 by using Cronbach's alpha has been reported.In order to analyze the data Pearson correlation and multivariate regression were used (Table 1).

\section{Results}

Given the significant level of correlation calculated in Table 1 and they can be concluded that successful identity style property there is a significant relationship between students' actual experience. Because a significant level of lower

Table 1. The correlation coefficient styles identity and style visionary experience.

\begin{tabular}{cccc}
\hline \multirow{2}{*}{ Identity style } & \multicolumn{2}{c}{ Style of concrete experience } & \multirow{2}{*}{ Sig. } \\
\cline { 2 - 3 } & Number & correlation coefficient & \\
\hline Successful identity & 100 & $0.465^{* *}$ & 0.001 \\
Suspension identity & 100 & 0.046 & 0.651 \\
Confusion & 100 & 0.047 & $0 . .643$ \\
Early identification & 100 & 0.102 & 0.311 \\
\hline
\end{tabular}


0.05 but the suspension identity, premature identity and identity confusion with style there is no significant relationship between students' actual experience. Because of the significance level is greater than 0.05 (Table 2).

F can be said with significance level test at least one of the predictor variables can predict the criterion variable regression model is meaningful to do (Table 3).

Standardized Beta chart shows assessment the contribution of each of the variables in the model's size offers. Large numbers indicate that the change in these variables predicted a severe impact on the single criterion variable.As a result of constant other variables with each unit increase in successful identity alters 0.66 concrete experiences the change in styles. Beta value for the variable in predicting successful identity (0.57), in which this factor suggests a positive impact on learning styles objective experience $\mathrm{T}$ and significant value to rough indication of the effect of predictor variables. These values are significant for successful identity but cannot be identified through other styles style concrete experience to predict (Table 4).

Given the significant level of correlation calculated in Table 4 and they can be concluded that a significant relationship between student achievement identity with styles reflective observation there. Because significance level of less than

Table 2. ANOVA, regression analysis.

\begin{tabular}{ccccccc}
\hline Model & Variable & Sum of squares & Df & Mean & F & Sig. \\
\hline & regression & 1783.322 & 4 & 445.83 & 8.721 & $0.001 \mathrm{a}$ \\
1 & Residual & 5120.668 & 95 & 53.90 & & \\
& Total & 6904.000 & 99 & & & \\
\hline
\end{tabular}

Table 3. Table of standard and non-standard beta coefficients.

\begin{tabular}{ccccccc}
\hline \multirow{2}{*}{ Variable } & \multicolumn{2}{l}{ Non-standardized coefficients } & standardized coefficients & T & Sig. \\
\cline { 2 - 5 } & $\mathrm{B}$ & $\mathrm{SD}$ & $\mathrm{B}$ & & & \\
\hline Fixed value & 18.472 & 4.342 & & & \\
Successful identity & 0.661 & 0.117 & 0.579 & 0.001 \\
Suspension identity & -0.124 & 0.095 & -0.134 & -1.306 & 0.195 \\
Confusion & -0.182 & 0.130 & -0.153 & -1.405 & 0.163 \\
Early identification & 0.030 & 0.111 & 0.026 & 0.268 & 0.789
\end{tabular}

Table 4. The correlation coefficient identity styles and learning styles reflective observation.

\begin{tabular}{cccc}
\hline & \multicolumn{3}{c}{ Learning styles reflective observation } \\
\hline identity styles & Number & correlation coefficient & Sig. \\
Successful identity & 100 & $0.379^{* *}$ & 0.001 \\
Suspension identity & 100 & 0.034 & 0.738 \\
Confusion & 100 & 0.094 & 0.354 \\
Early identification & 100 & 0.043 & 0.671 \\
\hline
\end{tabular}


0.05 , but the suspension identity, premature identity and identity confusion with style there is no significant relationship between students' reflective observation. Because a significant level of larger 0.05 (Table 5).

According significance level $\mathrm{F}$ test can be said, at least one of the predictor variables can predict the criterion variable regression model is meaningful to do (Table 6).

Large numbers indicate that the change of these variables predicted a more severe effect on the criterion variable. As a result of constant other variables with each unit increase in successful identity alters 0.49 reflect the change in the style of observational learning. Beta value for the variable in predicting successful identity (0.46) is obtained, which shows the positive impact of these factors on learning style is reflective observation $t$ and significant amounts refer to the overall effect of predictor variables makes this for successful identification and significant but cannot be identified through other style styles reflective observation to predict (Table 7).

Given the significant level of correlation calculated in Table 7 and concluded that they can be successful identity style property there is significant relationship between students' abstract conceptualization. Because significance level of less than 0.05 , but the suspension identity, premature identity and identity confusion

Table 5. One-way ANOVA of regression.

\begin{tabular}{ccccccc}
\hline Model & Variable & Sum of squares & Df & Mean & F & Sig. \\
\hline \multirow{2}{*}{1} & regression & 1003.290 & 4 & 250.822 & 4.7321 & $0.002 \mathrm{a}$ \\
& Residual & 5036.020 & 95 & 53.011 & & \\
& Total & 6039.310 & 99 & & & \\
\hline
\end{tabular}

Table 6. Table standard and non-standard beta coefficients.

\begin{tabular}{cccccc}
\hline \multirow{2}{*}{ Variable } & \multicolumn{2}{c}{ Nonstandardized coefficients } & Standardized coefficients & \multirow{2}{*}{ T } & Sig. \\
\cline { 2 - 3 } & $\mathrm{B}$ & $\mathrm{SD}$ & Beta & & \\
\hline Constant & 256 & 4.236 & & 4.220 & 0.001 \\
Successful identity & 0.493 & 0.116 & 0.461 & 4.233 & 0.001 \\
Suspension identity & -0.119 & 0.094 & -0.138 & -0.246 & 0.209 \\
Confusion & -0.025 & 0.129 & -0.022 & -0.193 & 0.848 \\
Early identification & -0.055 & 0.110 & 0.052 & -0.499 & 0.619 \\
\hline
\end{tabular}

Table 7. Correlation Coefficient identity styles and the style of abstract conceptualization.

\begin{tabular}{cccc}
\hline \multirow{2}{*}{ Identity styles } & \multicolumn{3}{c}{ Abstract conceptualization } \\
\cline { 2 - 4 } & Number & Correlation coefficient & Sig. \\
\hline Successful identity & 100 & $0.304^{* *}$ & 0.002 \\
Suspension identity & 100 & 0.196 & 0.051 \\
Confusion & 100 & 0.142 & 0.157 \\
Early identification & 100 & 0.118 & 0.241 \\
\hline
\end{tabular}


with style there is no significant relationship between students' reflective observation. Because a significant level of larger 0.05 (Table 8).

As table above, significance level test at least one of the predictor variables can predict the criterion variable for the regression model is significant (Table 9).

Table shows Standardized Beta to assess the contribution of each of the variables in the model's size offers. Large numbers indicate that the change in these variables predicted a severe impact on the single criterion variable. As a result, with all other variables constant rise in successful identity alters 0.43 any change in the style of abstract conceptualization learning and any other variables constant increase in the confusion caused Change -0.39 changes in the abstract conceptualization learning style in which Beta value for the variable in predicting successful identity (0.40), This factor suggests a positive impact on learning style is abstract conceptualization and beta value for the variable in predicting disoriented $(-0.35)$ obtained. This factor suggests a negative impact on learning style is abstract conceptualization. $\mathrm{T}$ and a significant amount to the overall effect of predictor variables mention of this. Successful identity and values is significant confusion but cannot be identified through other styles of abstract conceptualization learning style (Table 10).

Given the significant level of correlation calculated in Table 10 and concluded

Table 8. Regression analysis of variance.

\begin{tabular}{ccccccc}
\hline Model & Variable & Sum of squares & Df & Mean & F & Sig. \\
\hline \multirow{3}{*}{1} & regression & 1384.607 & 4 & 356.152 & 7.151 & $0.000 \mathrm{a}$ \\
& Residual & 4598.303 & 95 & 48.403 & & \\
& Total & 5982.910 & 99 & & & \\
\hline
\end{tabular}

Table 9. Table of standard and non-standard beta coefficients.

\begin{tabular}{|c|c|c|c|c|c|}
\hline \multirow{2}{*}{ Variable } & \multicolumn{2}{|c|}{ Nonstandardized coefficients } & \multirow{2}{*}{$\begin{array}{c}\text { Standardized coefficients } \\
\text { Beta }\end{array}$} & \multirow[t]{2}{*}{$\mathrm{T}$} & \multirow[t]{2}{*}{ Sig. } \\
\hline & B & SD & & & \\
\hline Constant & 29.579 & 4.134 & & 7.155 & 0.001 \\
\hline Successful identity & 0.433 & 0.111 & 0.407 & 3.887 & 0.001 \\
\hline Suspension identity & 0.182 & 0.090 & 0.212 & 1.946 & 0.050 \\
\hline Confusion & -0.393 & 0.123 & -0.354 & -3.200 & 0.002 \\
\hline Early identification & -0.144 & 0.105 & -0.136 & -1.369 & 0.171 \\
\hline
\end{tabular}

Table 10. The correlation coefficient identity and style styles abstract conceptualization.

\begin{tabular}{cccc}
\hline & \multicolumn{3}{c}{ Abstract conceptualization } \\
\hline Identity styles & Number & Correlation coefficient & Sig. \\
Successful identity & 100 & $0.342^{* *}$ & 0.001 \\
Suspension identity & 100 & 0.026 & 0.795 \\
Confusion & 100 & 0.015 & 0.879 \\
Early identification & 100 & 0.023 & 0.819 \\
\hline
\end{tabular}


that they can be successful identity style, there is a significant relationship between students' learning styles active experimentation. Because significance level of less than 0.05 , but suspension identity, identity confusion early and active experimentation with the style of the students there is no significant relationship. Because a significant level of larger 0.05 (Table 11).

According significance level F, it can be said, at least one of the predictor variables can predict the criterion variable for the regression model is significant (Table 12).

Large numbers indicate that the change in these variables predicted a severe impact on the single criterion variable. As a result, with all other variables constant rise in successful identity alters 0.54 any change in the style of experimentation is activated beta value for the variable in predicting successful identity (0.13) results with the positive impact of on the style of that is active experimentation and the effect of significant predictor variables rough indication of this. Significant amounts successful identity but through other forms of identity cannot be predicted active experimentation learning style.

\section{Discussion and Conclusion}

Results showed a significant difference was observed as successful identity style property there is a significant relationship between students' actual experience. The result of the research of [9] [10] is aligned and consistent. As human beings in different dimensions have differences, and these differences in abilities, talents, desire and ultimately enhanced their learning style, understanding learning styles of students and guiding them in selecting the appropriate field of study, This allows us to provide them with knowledge, issues with your interests and qualifications adapted and the psychological environment and their academic career and secured and in that environment, their abilities and skills to operate

Table 11. Regression analysis of variance.

\begin{tabular}{ccccccc}
\hline Model & Variable & Sum of square & df & Mean & F & Sig. \\
\hline & regression & 1193.897 & 4 & 268.474 & 4.543 & $0.002^{\mathrm{a}}$ \\
Active experimentation style & Residual & 6241.013 & 95 & 65.695 & & \\
& Total & 7434.910 & 99 & & & \\
\hline
\end{tabular}

Table 12. Table of standard and non-standard beta coefficients.

\begin{tabular}{|c|c|c|c|c|c|}
\hline \multirow{2}{*}{ Variable } & \multicolumn{2}{|c|}{ Nonstandardized coefficients } & \multirow{2}{*}{$\begin{array}{c}\text { Standardized coefficients } \\
\text { Beta }\end{array}$} & \multirow{2}{*}{$\mathrm{T}$} & \multirow{2}{*}{ Sig. } \\
\hline & $\mathrm{B}$ & $\mathrm{SD}$ & & & \\
\hline Constant & 23.753 & 4.816 & & 4.932 & 0.000 \\
\hline Successful identity & 0.549 & 0.130 & 0.463 & -1.565 & 0.000 \\
\hline Suspension identity & -0.164 & 0.105 & -0.171 & -0.806 & 0.121 \\
\hline Confusion & -0.115 & 0.143 & -0.093 & -0.093 & 0.422 \\
\hline Early identification & -0.042 & 0.123 & -0.036 & -0.036 & 0.731 \\
\hline
\end{tabular}


and bring to fruition their true talent. Thus, according to different academic and professional interest and learning styles, individual guidance in the areas of education and a good job is their increased motivation and empowerment. Since identity styles associated with information processing and dealing with the problem is, it can be inferred that identity styles may have an impact on learning styles. Education and Psychology research findings of scientists in the field of learning, new horizons have opened up for mankind. This finding makes the teaching and learning as an activity is not random, but a regular scientific process to be considered. By understanding the learning styles of students not only have helped them in teaching and learning but can be any suitable person to lead the field of study and career.

According to the students in terms of identity styles are different and observing that the identity of each of the styles associated with specific learning styles, it can be concluded that students with different learning styles can be different identity that these factors could be the reason Relationship between identity styles and learning styles. People who've managed to find an identity, an era of clear commitments and specific search behind and have created for themselves. They take the job seriously and considered various options to suit your circumstances and decisions have talent.

The final choices as they may be converted from their parents' wishes. If they are exposed to sudden changes in your environment does not open because the power of flexibility is strong in relation to the surrounding world. They are thoughtful and internal locus of control and at times the exposure to a stressful event, have better cognitive function. At the time of judgment, their internal criteria are less dependent on the opinions and ideas of others [14]. The findings show that each substation identity to be associated with specific learning styles and the connections made between identity styles and learning styles that students can learn the lessons better and self-learning and self-satisfied as to form a positive self-concept to be learners.

The limitation of this study concerned with the participants of the study who refused to participate in the survey. Moreover, future studies can expand the findings of the current study by considering other mediating variables.

\section{References}

[1] Berzonsky, M.D. and Kuk, L.S. (2005) Identity Style, Psychological Maturity, and Academic Performance. Personality and Individual Differences, 39, 235-247.

[2] Christou, N. and Dinov, I.D. (2010) A Study of Students' Learning Styles, Discipline Attitudes and Knowledge Acquisition in Technology-Enhanced Probability and Statistics Education. Journal of Online Learning and Teaching, 6, 546-572.

[3] Crocetti, E., Rubini, M., Luyckx, K. and Meeus, W. (2008) Identity Formation in Early and Middle Adolescents from Various Ethnic Groups: From Three Dimensions to Five Statuses. Journal of Youth and Adolescence, 37, 983-996. https://doi.org/10.1007/s10964-007-9222-2

[4] DecCecc, J.P. and Crowfor, R.C. (1974) The Psychology of Learning and Instruction: Educational Psychology. 2nd Edition, Prentice-Hall, Englewood Cliffs, NJ. 
[5] Demirkan, H. and Demirbas, O. (2010) The Effects of Learning Styles and Gender on the academic Performance of interior Architecture Students. Procedia-Social and Behavioral Sciences, 2, 1390-1394.

[6] Goosens, L. (2001) Global versus Domain-Specific Statuses in Identity Research: A Comparison of Two Self-Report Measures. Journal of Youth and Adolescence, 24, 681-699.

[7] Ahmadi, S. and Ahmedi, M. (2011) The Relationship between Math Anxiety and Learning Styles of Students. Research on Curriculum, 8, 31-89.

[8] Biabangard, E. (2007) Adolescent Psychology. 11th Edition, Islamic Culture Publications Office, Tehran.

[9] Bayrami, M. (2010) Compare the Styles, Identity, Identity Types in Male and Female Students. Journal of Psychology, 25, 58-69.

[10] Ghorbani, A.R., Mohammadi, R. and Kochaki Ashour, M. (2006) Check the Status of Style, Identity and Its Relationship to Public Health and Social and Economic Status. www.SID.ir

[11] Hosseini Largani, M. (2000) The Relationship between Students' Learning Styles Bachelor, Master, Strong and Weak Men and Women Three Disciplines of the Humanities, Medical and Technical and Technical Engineering. Master's Universities, Allameh Tabatabaei University.

[12] Homayouni, A.R. and Kadivar, P. (2006) The Relationship between Learning Styles, Cognitive Styles and Selection of Courses in High School Students. Iranian Psychologists, 3, 144-137.

[13] Hashemi, L. (2004) Examine the Evolution of the Situation of Iranian Identity from the Perspective of Adolescents and Young Adults 12 - 24 Years Marcia. Shiraz University Psychology Master's Thesis.

[14] Halimi, H. (2015) Students' Learning Styles and Identity Styles. Bachelor Thesis of Psychology, Payame Noor University, Torbat-e Jam, Iran.

[15] Hichson, J. and Baltimore, M. (1996) Gender Related Learning Style Patterns of Middle School Pupils. School Psychology International, 17, 59-70.

[16] Parsa, M. (2001) Learning Psychology-Based Theories. 3rd Edition, Publication of Shokohan, Tehran.

[17] Rassool, G.H. and Rawaf, S. (2007) Learning Style Preferences of Undergraduate Nursing Students. Nursing Standard, 21, 35-41.

https://doi.org/10.7748/ns.21.32.35.s51

[18] Shokrabi, Z. and Eskandari, H. (2004) Evaluation and Comparison of Identity between Male and Female. www.SID.ir

[19] Smith, P. and Dalton, J. (2005) Getting to Grips with Learning Styles. The National Center for Vocational Education Research. Deokin University, Adelaide.

[20] Tanwir, U.H., Aditya, K.S. and Banshi, D. (2010) An Investigation of Relationship between Learning Styles and Performance of Learners. International Journal of Engineering Science and Technology, 2, 2813-2819.

[21] Woolfolk, A.E. (2004) Educational Psychology. 3rd Edition, Prentice-Hall, Englewood Cliffs, NJ.

[22] Kalbasi, S., Nasseri, M., Sharif-Zadeh, G. and Poor Zero, A. (2009) Birjand University Students' Learning Style. Medical Stages of Development, 6, 16-10.

[23] Kroger, J. (2004) Identity in Adolescence: The Balance between Self and Other. Routledge, London \& New York. https://doi.org/10.4324/9780203346860

[24] Khaksar Boldachi, M. (2005) The Relationship of Learning Styles, Self-Concept and 
Discipline at the High School Students. Journal of Educational Innovations, No. 14.

[25] Kolb, D.A. (2005) Learning Style Inventory: Technical Specification. Resource Direct, Boston.

[26] Kimble, G.A. (1961) Hilgaral and Marquis Conditioning and Learning. 2nd Edition, Prentice-Hall, Englewood Cliffs, NJ.

[27] Luyckx, K., Goossens, L., Soenens, B., Beyers, W. and Vansteenkiste, M. (2005) Identity Statuses Based on 4 Rather than 2 Identity Dimensions: Extending and Refining Marcia's Paradigm. Journal of Youth and Adolescence, 34, 605-618. https://doi.org/10.1007/s10964-005-8949-x

[28] Marcia, J.E. (1966) Development and Validation of Ego Identity Status. Journal of Personality and Social Psychology, 3, 551-558. https://doi.org/10.1037/h0023281

Submit or recommend next manuscript to SCIRP and we will provide best service for you:

Accepting pre-submission inquiries through Email, Facebook, LinkedIn, Twitter, etc. A wide selection of journals (inclusive of 9 subjects, more than 200 journals)

Providing 24-hour high-quality service

User-friendly online submission system

Fair and swift peer-review system

Efficient typesetting and proofreading procedure

Display of the result of downloads and visits, as well as the number of cited articles

Maximum dissemination of your research work

Submit your manuscript at: http://papersubmission.scirp.org/

Or contact ojpsych@scirp.org 